\title{
Hemodynamic Implications of Carbon Monoxide (CO) and Nitrogen Oxide (NO) during Living Donor Liver Transplantation
}

\author{
Hyunyoung Lim, ${ }^{1}$ Suk-Koo Lee $^{2}$ and Gaabsoo Kim ${ }^{3}$ \\ ${ }^{1}$ Department of Anesthesiology and Pain Medicine, Hanyang University Medical Center, Seoul, Republic of Korea \\ ${ }^{2}$ Department of Surgery, Samsung Medical Center, Sungkyunkwan University School of Medicine, Seoul, \\ Republic of Korea \\ ${ }^{3}$ Department of Anesthesiology and Pain Medicine, Samsung Medical Center, Sungkyunkwan University School \\ of Medicine, Seoul, Republic of Korea
}

Carbon monoxide (CO) and nitrogen oxide (NO) affect vasodilation and cause hemodynamic change. Hemodynamic instability due to liver transplantation may result in poor prognosis of graft. This study investigated the hemodynamic implications of $\mathrm{CO}$ and $\mathrm{NO}$ levels measured using carboxyhemoglobin $(\mathrm{COHb})$ and methemoglobin (MetHb) during living donor liver transplantation (LDLT). The hemodynamic instability with a pressor dose (norepinephrine equivalent) was estimated 1 hour after graft reperfusion. $\mathrm{COHb}$ and $\mathrm{MetHb}$ were used as indexes of $\mathrm{CO}$ and $\mathrm{NO}$, and were measured using an arterial blood gas analyzer. One hundred and ten recipients who underwent LDLT from May 2011 to July 2013 were selected. Recipients were divided into high $(\geq 1.9 \%)$ and low $(<1.9 \%) \mathrm{COHb}$ groups with $\mathrm{COHb}$ concentrations at 5 minutes after reperfusion. Recipients were also divided into high ( $\geq 0.4 \%)$ and low $(<0.4 \%)$ MetHb groups with MetHb concentrations at 30 minutes after reperfusion. Data are presented as mean \pm standard deviation or number (percentage). Model for End-stage Liver Disease (MELD) scores were different for the two $\mathrm{COHb}$ groups (low: $13.4 \pm 9.0$ vs. high: $19.7 \pm 10.6, p<0.001$ ), and pressor doses adjusted by MELD scores were also different between the two $\mathrm{COHb}$ groups (low: $0.09 \pm 0.01 \mu \mathrm{g} / \mathrm{kg} / \mathrm{min}$ vs. high: $0.14 \pm 0.01$ $\mu \mathrm{g} / \mathrm{kg} / \mathrm{min}, \mathrm{p}=0.029)$. By contrast, pressor doses and MELD scores were not different between the two $\mathrm{MetHb}$ groups. In conclusion, $\mathrm{CO}$ rather than NO has hemodynamic implications during LDLT. Therefore, the increase in $\mathrm{COHb}$ during LDLT is predictive of hemodynamic instability.

Keywords: carbon monoxide; carboxyhemoglobin; living donor liver transplantation; methemoglobin; nitrogen oxide Tohoku J. Exp. Med., 2017 November, 243 (3), 179-186. C 2017 Tohoku University Medical Press

\section{Introduction}

Carbon monoxide (CO) and nitrogen oxide (NO) have a number of functions in vivo. The physical and pharmacological roles of NO have been extensively studied in experimental and clinical models in recent decades (Gladwin et al. 2004; Lee et al. 2007; Hon et al. 2010; Hare et al. 2013). In contrast, our awareness of $\mathrm{CO}$ as a mediator of cardiovascular homeostasis and a maintenance factor in organ function developed relatively recently.

Both $\mathrm{CO}$ and $\mathrm{NO}$ are produced by enzymes in vivo and related with heme protein. Endogenous $\mathrm{CO}$ is produced by heme oxygenase and $\mathrm{NO}$ is synthesized from NO synthase. Both increase the formation of cyclic guanosine monophosphate from guanosine triphosphate and serve to lower vascular tone. $\mathrm{CO}$ tightly binds with hemoglobin and forms carboxyhemoglobin $(\mathrm{COHb})$, which is slowly reconverted to hemoglobin in the presence of sufficient oxygen concentrations (Takeda et al. 2002). In the presence of NO, hemo- globin with ferrous heme is converted to hemoglobin with ferric heme (methemoglobin, MetHb). MetHb is reconverted to hemoglobin with ferrous heme through two enzyme systems, cytochrome $b_{5}$ MetHb reductase and nicotinamide-adenine-dinucleotide-phosphate MetHb reductase. The former is responsible for removal of $95 \%$ of endogenous MetHb (Lee and Lee 2013). One study demonstrated that the increased concentration of $\mathrm{COHb}$ in liver transplantation is associated with initial function of the transplanted liver (Ali et al. 2007). The extent of damage can be estimated through expired $\mathrm{CO}$ levels after reperfusion in liver transplantation (Matsusaki et al. 2008). However, there are not yet studies about $\mathrm{COHb}$ and $\mathrm{MetHb}$ as predictors of hemodynamic change due to $\mathrm{CO}$ and $\mathrm{NO}$ during living donor liver transplantation (LDLT). This study investigated the hemodynamic implications of $\mathrm{CO}$ and NO levels based on $\mathrm{COHb}$ and $\mathrm{MetHb}$ as indexes during LDLT.

Received July 7, 2017; revised and accepted October 31, 2017. Published online November 23, 2017; doi: 10.1620/tjem.243.179.

Correspondence: Gaabsoo Kim, Department of Anesthesiology and Pain Medicine, Samsung Medical Center, Sungkyunkwan University

School of Medicine, 81 Irwon-ro, Gangnam-gu, Seoul 06351, Republic of Korea.

e-mail: gskim@skku.edu 


\section{Methods}

Subjects

The Institutional Review Board of Samsung Medical Center approved this retrospective study and waived the requirement for written informed consent (SMC 2014-09-090-003). Medical records of 300 recipients who underwent elective LDLT from May 2011 to July 2013 were initially screened. One case of re-transplantation, 24 cases of pediatric liver transplantation, 82 cases of deceased donor liver transplantation, 34 cases of unmounted pulmonary artery catheter, and 11 cases of aberrant gas analysis were excluded from the study. Thirty-eight recipients who were transfused with allogeneic packed red blood cells until 5 minutes after reperfusion were excluded. Conversely, 40 recipients who were transfused with Cell Saver (Haemonetics, Cell Saver ${ }^{\circledR} 5$, USA) blood until 5 minutes after reperfusion were included. Finally, 110 recipients were chosen as subjects.

\section{Anesthetic care}

Anesthetic management was conducted according to our institutional liver transplantation protocol. Induction was performed with 5 $\mathrm{mg} / \mathrm{kg}$ thiopental sodium and sevoflurane, and maintained with isoflurane. The bispectral index was monitored and maintained in the 40-60 range. Mechanical ventilation was delivered at tidal volume of $8-10 \mathrm{ml} / \mathrm{kg}$ using a mixture of oxygen and medical air at a flow rate of $2 \mathrm{~L} / \mathrm{min}$. Mechanical ventilation was controlled to maintain normocapnea. Direct blood pressure was monitored via the right radial artery, right femoral artery, right femoral vein, and right internal jugular vein. A large-bore central venous catheter was placed in combination with a pulmonary arterial catheter (Swan-Ganz CCOmboV, Edward Lifesciences, LLC, Irvine, CA). The protocol aimed to maintain mean arterial pressure $\geq 70 \mathrm{mmHg}$, and the following was performed if mean arterial pressure was below $70 \mathrm{mmHg}$ : adjustment of anesthetic depth to maintain a bispectral index of 40-60, fluid and blood product infusion to maintain central venous pressure $\geq 5$ $\mathrm{mmHg}$, administration of dopamine to maintain right ventricular ejection fraction $\geq 40$, and administration of norepinephrine to maintain systemic vascular resistance $\geq 600 \mathrm{dyn} \cdot \mathrm{s} / \mathrm{cm}^{5}$. The rate of pressor infusion was recorded. Body temperature was maintained in the normal range using a whole-body convective warming blanket, room temperature set at $24^{\circ} \mathrm{C}$, and a rapid fluid warmer.

\section{Data collection}

In all patients, preoperative data such as age, sex, body weight, height, model for end-stage liver disease (MELD) score, and graft recipient weight ratio were collected. Pressor dose was measured one hour after graft reperfusion, and pressor dose was expressed with norepinephrine equivalent. The relative potency of dopamine and norepinephrine were 1:100 (De Backer et al. 2010). Because smoking can affect the concentration of $\mathrm{COHb}$, the proportion of non-smokers, ex-smokers, and current smokers was analyzed.

$\mathrm{COHb}$ and MetHb were used as indexes of $\mathrm{CO}$ and $\mathrm{NO}$. The concentration of $\mathrm{COHb}$ and $\mathrm{MetHb}$ were measured in percentage using an arterial blood gas analyzer (RAPIDLab ${ }^{\circledR} 1265$, SIEMENS, Tarrytown NY, USA). Arterial blood gas analysis was performed six times: after induction of anesthesia (Time 1), at the beginning of the anhepatic phase (Time 2), at 10 minutes before reperfusion (Time 3), at 5 minutes after reperfusion (Time 4), at 30 minutes after reperfusion (Time 5), and at 1 hour after reperfusion (Time 6).
Maximal oxidative stress occurs just after reperfusion. Because CO has 200 times higher affinity for hemoglobin than oxygen, the concentration of $\mathrm{COHb}$ in blood immediately reaches the highest level (Peterson and Stewart 1970). COHb was divided into two groups at Time 4. There has been little research on the time course of $\mathrm{MetHb}$, such as affinity for hemoglobin and half-life. Hon et al. (2010) reported that MetHb reached its maximum concentration at 30 minutes after administration of sodium nitrite. Accordingly, patients were divided into high and low MetHb groups with MetHb concentrations at 30 minutes after reperfusion.

The postoperative course of patients was assessed by aspartate aminotransferase (AST) and alanine aminotransferase (ALT) at 1, 2, 3,5 , and 7 days after surgery in both low and high groups of $\mathrm{COHb}$ and MetHb.

\section{Statistics}

Data are presented as mean \pm standard deviation (SD) or number and percentage. Continuous variables were compared with MannWhitney $U$ test or independent T-test according to KolmogorovSmirnov Z test, and categorical values were compared with Chisquare test. In $\mathrm{COHb}$, the pressor dose at Time 6 was compared between two groups with Analysis of Covariance (ANCOVA) test adjusted by MELD score. The value is represented as mean \pm standard error. Repeated measures ANOVA using Bonferroni correction for post-hoc analysis was used for AST and ALT at 1, 2, 3, 5, and 7 days after surgery. The correlation analysis for continuous values was evaluated through Pearson correlation analysis. Data were considered significant at $\mathrm{p}$-value is less than 0.05 (two-tailed). All statistical analyzes were performed using SPSS (version 22.0, SPSS Inc., Chicago, IL, USA).

\section{Results}

\section{Division into two $\mathrm{COHb}$ groups}

Fig. 1 shows the distribution of $\mathrm{COHb}$ at 5 minutes after reperfusion in all patients. The mean \pm standard devi-

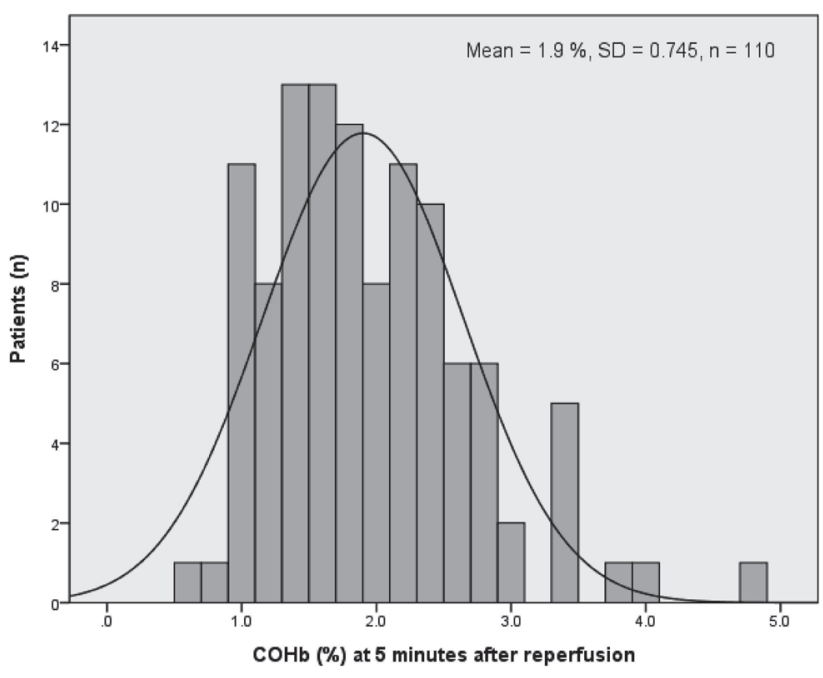

Fig. 1. Distribution of COHbs 5 minutes after reperfusion of patients.

Mean \pm SD of all patients 5 minutes after reperfusion is $1.901 \pm 0.745 \%$. Patients were divided into high $(\mathrm{COHb}$ $\geq 1.9 \%)$ and low groups $(\mathrm{COHb}<1.9 \%)$. $\mathrm{COHb}$, carboxyhemoglobin; $\mathrm{SD}$, standard deviation. 
ation was $1.90 \pm 0.764 \%$. The patients were divided into high $(\mathrm{COHb} \geq 1.9 \%)$ and low groups $(\mathrm{COHb}<1.9 \%)$.

\section{Comparison of characteristics between two $\mathrm{COHb}$ groups}

Patient data did not vary between the two groups except for MELD score (low COHb group: $13.4 \pm 9.0$, high $\mathrm{COHb}$ group: $19.7 \pm 10.6, \mathrm{p}<0.001)$ and patients trans- fused with Cell Saver blood (low COHb group: $32.5 \%$ and high $\mathrm{COHb}$ group: $67.5 \%, \mathrm{p}=0.001)($ Table 1$)$.

\section{Comparison of pressor dose between two COHb groups}

At one hour after reperfusion, the proportion of patients with infusion of pressor was similar between the two groups (Table 2). Pressor doses were significantly dif-

Table 1. Comparison of patients in low and high $\mathrm{COHb}$ groups.

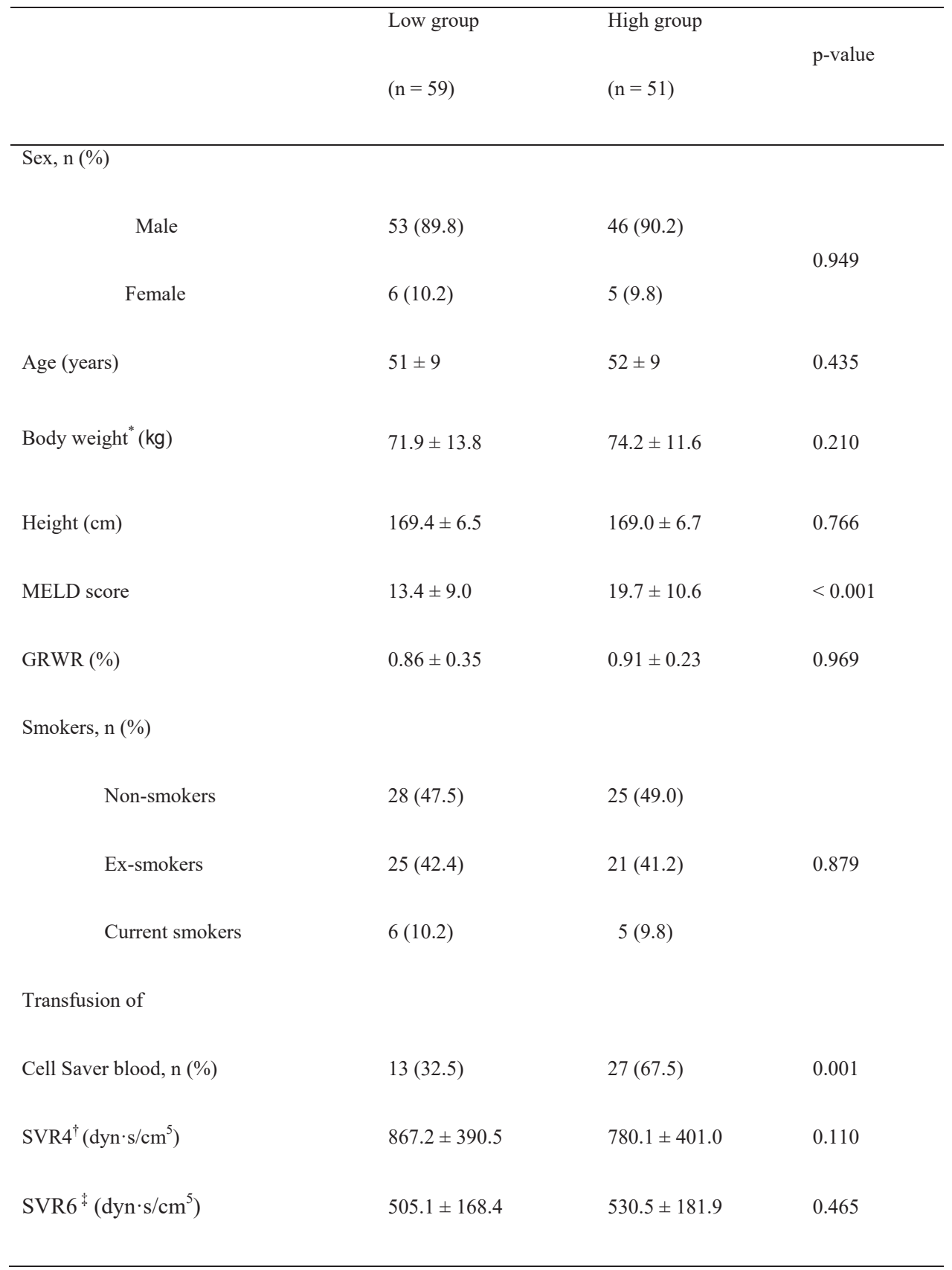

Low group: $\mathrm{COHb}<1.9 \%$ at 5 minutes after reperfusion, High group: $\mathrm{COHb} \geq 1.9 \%$ at 5 minutes after reperfusion. Data are presented as mean \pm SD or number and percentage. p-values are results of Mann-Whitney $U$ test or independent T-test according to KolmogorovSmirnov $\mathrm{Z}$ test for continuous data and chi-square test for categorical values. $\mathrm{COHb}$, carboxyhemoglobin; MELD, model for end-stage liver disease; GRWR, graft recipient weight ratio; SVR, systemic vascular resistance. *body weight except for amount of ascites. †five minutes after reperfusion, ${ }^{\star}$ one hour after reperfusion. 
Table 2. Comparison of variable parameters of pressors at one hour after reperfusion in low and high $\mathrm{COHb}$ groups.

\begin{tabular}{clll}
\hline & Low group & High group & p-value \\
& $(\mathrm{n}=59)$ & $(\mathrm{n}=51)$ & \\
\hline Proportion of patients with pressors, $\mathrm{n}(\%)$ & & & \\
Used & $50(84.7)$ & $48(94.1)$ & 0.137 \\
Non-used & $9(15.3)$ & $3(5.9)$ &
\end{tabular}

Dose of pressors $(\mu \mathrm{g} / \mathrm{kg} / \mathrm{min})$

Non-adjusted

Adjusted
$0.09 \pm 0.09$

$0.09 \pm 0.01^{*}$
$0.14 \pm 0.09$

$0.14 \pm 0.01^{*}$
0.001

0.029

Low group: $\mathrm{COHb}<1.9 \%$ at 5 minutes after reperfusion, High group: $\mathrm{COHb} \geq 1.9 \%$ at 5 minutes after reperfusion. Data are presented as means \pm SD or number and percentage. p-values are results of Mann-Whitney $U$ test according to Kolmogorov-Smirnov Z test and Analysis of Covariance (ANCOVA) for continuous values, and Chi-square test for categorical values. *mean ( \pm standard error) dose of pressors adjusted by model for end-stage liver disease (MELD) score.

$\mathrm{COHb}$, carboxyhemoglobin.

ferent between the two groups (low $\mathrm{COHb}$ group: $0.09 \pm$ $0.09 \mu \mathrm{g} / \mathrm{kg} / \mathrm{min}$ and high $\mathrm{COHb}$ group: $0.14 \pm 0.09 \mu \mathrm{g} / \mathrm{kg} /$ min, $\mathrm{p}=0.001$ ). With the Analysis of Covariance (ANCOVA) test to adjust MELD score, pressor dose was significantly different between the two groups (mean \pm standard error, low COHb group: $0.09 \pm 0.01 \mu \mathrm{g} / \mathrm{kg} / \mathrm{min}$ and high $\mathrm{COHb}$ group: $0.14 \pm 0.01 \mu \mathrm{g} / \mathrm{kg} / \mathrm{min}, \mathrm{p}=0.029$ ). This indicates that increased $\mathrm{COHb}$ after ischemia/reperfusion can predict hemodynamic instability.

\section{Division into two MetHb groups}

Fig. 2 shows the distribution of MetHb at 30 minutes after reperfusion in all patients. The mean \pm standard deviation was $0.380 \pm 0.166 \%$. Patients were divided into high (MetHb $\geq 0.4 \%$ ) and low groups (MetHb $<0.4 \%$ ).

Comparison of characteristics and pressor dose between two MetHb groups

Patient data did not vary between the two groups, including MELD score. Pressor doses at one hour after reperfusion and the proportion of patients with pressor were not significantly different between the two groups (Tables 3 and 4).

Correlation analysis among MELD score, $\mathrm{COHb}$, and pressor dose

A correlation among preoperative MELD score, $\mathrm{COHb}$ at 5 minutes after reperfusion, and pressor doses at 1 hour

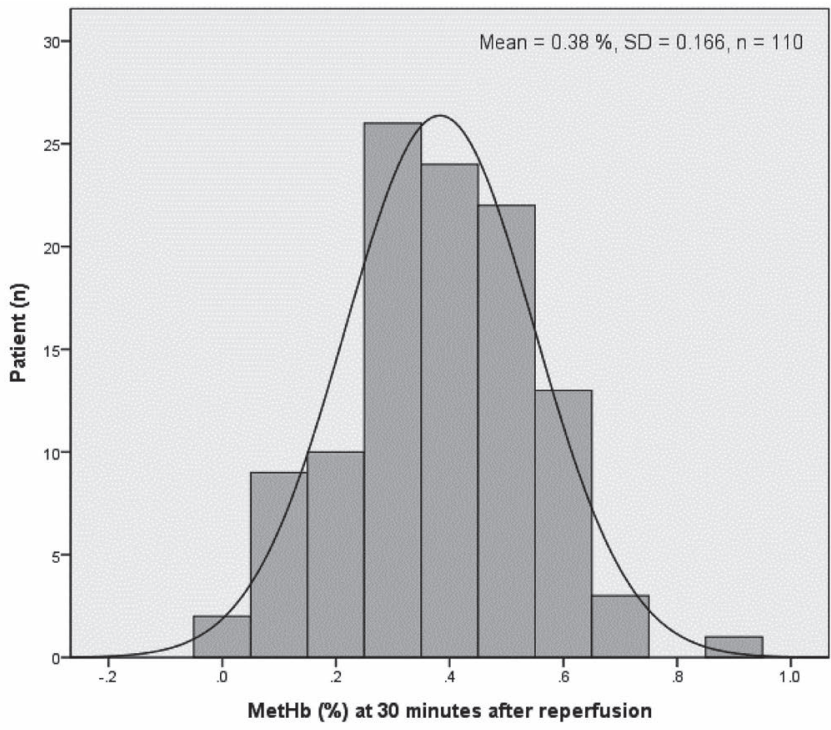

Fig. 2. Distribution of MetHbs at 30 minutes after reperfusion for all patients.

Mean \pm SD of all patients at 30 minutes after reperfusion is $0.380 \pm 0.166 \%$. Patients were divided into high (MetHb $\geq 0.4 \%$ ) and low groups (MetHb $<0.4 \%$ ). $\mathrm{MetHb}$, methemoglobin; SD, standard deviation.

after reperfusion were observed. There was moderate correlation between the $\mathrm{COHb}$ and pressor doses (correlation coefficient $=0.342, \mathrm{p}<0.001)$. Weak correlation was also seen between preoperative MELD scores and pressor doses 
Table 3. Comparison of patients in low and high MetHb groups.

\begin{tabular}{|c|c|c|c|}
\hline & Low group & High group & \\
\hline & $(\mathrm{n}=47)$ & $(\mathrm{n}=63)$ & $\mathrm{p}$-value \\
\hline Sex, n (\%) & & & \\
\hline Male & $44(93.6)$ & $55(87.3)$ & \\
\hline & & & 0.275 \\
\hline Female & $3(6.4)$ & $8(12.7)$ & \\
\hline $\operatorname{Age}(y r)$ & $53 \pm 9$ & $50 \pm 9$ & 0.249 \\
\hline Body weight $(\mathrm{kg})^{*}$ & $72.8 \pm 13.4$ & $73.0 \pm 12.5$ & 0.840 \\
\hline Height $(\mathrm{cm})$ & $169.0 \pm 6.0$ & $169.4 \pm 7.0$ & 0.743 \\
\hline MELD score & $16.2 \pm 11.7$ & $16.4 \pm 9.1$ & 0.251 \\
\hline GRWR (\%) & $0.85 \pm 0.32$ & $0.91 \pm 0.28$ & 0.265 \\
\hline Transfusion of & & & \\
\hline Cell Saver blood, n (\%) & $19(40.4)$ & $21(33.3)$ & 0.444 \\
\hline $\mathrm{SVR} 4^{\dagger}\left(\mathrm{dyn} \cdot \mathrm{s} / \mathrm{cm}^{5}\right)$ & $870.0 \pm 346.8$ & $794.6 \pm 428.9$ & 0.064 \\
\hline $\mathrm{SVR}^{*}\left(\mathrm{dyn} \cdot \mathrm{s} / \mathrm{cm}^{5}\right)$ & $547.3 \pm 175.4$ & $494.1 \pm 171.6$ & 0.126 \\
\hline
\end{tabular}

Low group: MetHb $<0.4 \%$ at 30 minutes after reperfusion, High group: MetHb $\geq 0.4 \%$ at 30 minutes after reperfusion. Data are presented as mean $\pm \mathrm{SD}$ or number and percentage. p-values are the result of Mann-Whitney $U$ test and independent T-test according to Kolmogorov-Smirnov $\mathrm{Z}$ test for continuous values and chi-square test for categorical values. MetHb, Methemoglobin; MELD, model for end-stage liver disease; GRWR, graft recipient weight ratio; SVR, systemic vascular resistance. *body weight except for amount of ascites, five minutes after reperfusion, tone hour after reperfusion.

at one hour after reperfusion (correlation coefficient $=$ $0.284, p=0.003$ ). Moderate correlation was seen between preoperative MELD scores and $\mathrm{COHb}$ at 5 minutes after reperfusion (correlation coefficient $=0.496, p<0.001$ ) (Table 5).

Correlation analysis between $\mathrm{COHb}$ at 5 minutes and MetHb at 30 minutes after reperfusion

There was weak correlation between $\mathrm{COHb}$ at $5 \mathrm{~min}$ utes after reperfusion and $\mathrm{MetHb}$ at 30 minutes after reperfusion, but not significant (correlation coefficient $=0.176, \mathrm{p}$ $=0.065$ ).
Comparison of postoperative aspartate aminotransferase and alanine aminotransferase

There were no significant differences in AST and ALT between the low and high $\mathrm{COHb}$ groups (Fig. 3). There were also no significant differences in AST and ALT between the low and high MetHb groups.

\section{Discussion}

Various endogenous hormones and monoxides are related to vascular tone adjustment. Many studies (Gladwin et al. 2004; Lee et al. 2007) indicate that NO lowers systemic vascular resistance in patients with end-stage liver disease, but there are few studies on the effects of CO. Takeda et al. (2002) reported that organ perfusion and function is affected by monoxide gas mediators during abdomi- 
Table 4. Comparison of variable parameters of pressors at one hour after reperfusion in low and high MetHb groups.

\begin{tabular}{cccc}
\hline & Low group & High group & p-value \\
& $(\mathrm{n}=47)$ & $(\mathrm{n}=63)$ & \\
\hline Proportion of patients with pressors, $\mathrm{n}(\%)$ & & $56(88.9)$ & 0.937 \\
Non-used & $42(89.4)$ & $7(11.1)$ & \\
Dose of pressors $(\mu \mathrm{g} / \mathrm{kg} / \mathrm{min})$ & $5(10.6)$ & & 0.976
\end{tabular}

Low group: MetHb $<0.4 \%$ at 30 minutes after reperfusion, High group: MetHb $\geq 0.4 \%$ at 30 minutes after reperfusion. Data are presented as means \pm SD or number and percentage. p-values are the result of Mann-Whitney $\mathrm{U}$ test according to Kolmogorov-Smirnov Z test for continuous values and Chi-square test for categorical values.

$\mathrm{MetHb}$, methemoglobin.

Table 5. Pearson correlation coefficient for MELD score, $\mathrm{COHb}$ and pressor dose.

\begin{tabular}{|c|c|c|}
\hline & MELD score ${ }^{\dagger}$ & $\mathrm{COHb}^{4}$ \\
\hline $\mathrm{COHb}^{\ddagger}$ & $0.496^{*}$ & \\
\hline Pressor dose $\mathrm{e}^{\S}$ & $0.284^{*}$ & $0.342^{*}$ \\
\hline
\end{tabular}

\footnotetext{
$* \mathrm{P}<0.05$.

MELD, model for end-stage liver disease; $\mathrm{COHb}$, carboxyhemoglobin. " before liver transplantation, ${ }^{\star}$ five minutes after reperfusion, §one hour after reperfusion.
}

nal surgery. De Las Heras et al. (2003) claimed that heme oxygenase activity and expression is increased in liver tissues of patients with liver cirrhosis, and this was confirmed by $\mathrm{COHb}$ concentration. The concentration of $\mathrm{COHb}$ in patients with end-stage liver disease was $1.0 \pm 0.1 \%$, which is significantly higher than the value in healthy people $(0.6$ $\pm 0.1 \%$ ). Hayashi et al. (2004) stated that heme oxygenase is induced by oxidative stress not only in surgery but also in sepsis, systemic inflammation, and organ dysfunction. They also indicated that $\mathrm{COHb}$ can be used as a marker for oxidative stress. If someone has hypoxic damage or oxidative stress due to ischemia/reperfusion injury, $\mathrm{CO}$ and $\mathrm{NO}$ are generated from cells. During liver transplantation in patients with end-stage liver disease, oxidative stress caused by ischemia/reperfusion injury can lower systemic vascular resistance and worsen hemodynamic instability. During the post-reperfusion period of liver transplantation, hemodynamic instability can reduce blood flow to the graft, liver function recovery may be delayed, and outcomes may be worse. Because the pressor dose was proportional to hemodynamic instability, we studied the relationship of hemody- namic instability to changes in $\mathrm{CO}$ and $\mathrm{NO}$ and the dose of pressor.

The concentration of $\mathrm{CO}$ is determined through gas analysis directly from the breath. However, CO has 200 times higher affinity for hemoglobin than oxygen. Hemoglobin immediately couples with $\mathrm{CO}$, and the concentration of $\mathrm{COHb}$ in blood immediately reaches the highest level (Peterson and Stewart 1970). Because co-oximetry blood gas analyzer (hemoglobin, oxyhemoglobin, carboxyhemoglobin, methemoglobin, and oxygen saturation) is commonly used during liver transplantation, $\mathrm{COHb}$ was used as an index of generated CO. Indeed, Matsusaki et al. (2008) reported a significant correlation between the concentration of $\mathrm{CO}$ and $\mathrm{COHb} 5$ minutes after reperfusion.

Typically, smokers have a higher concentration of $\mathrm{CO}$ in blood than non-smokers. Tran et al. (2007) reported that the normal range of $\mathrm{COHb}$ is $0-1.5 \%$ in ordinary persons and $4-9 \%$ in smokers. However, the half-life of $\mathrm{COHb}$ was 320 minutes (Peterson and Stewart 1970). Patients were divided by $\mathrm{COHb}$ concentration at 5 minutes after reperfusion. The effects of smoking may be not significant. 
$\mathrm{COHb}$
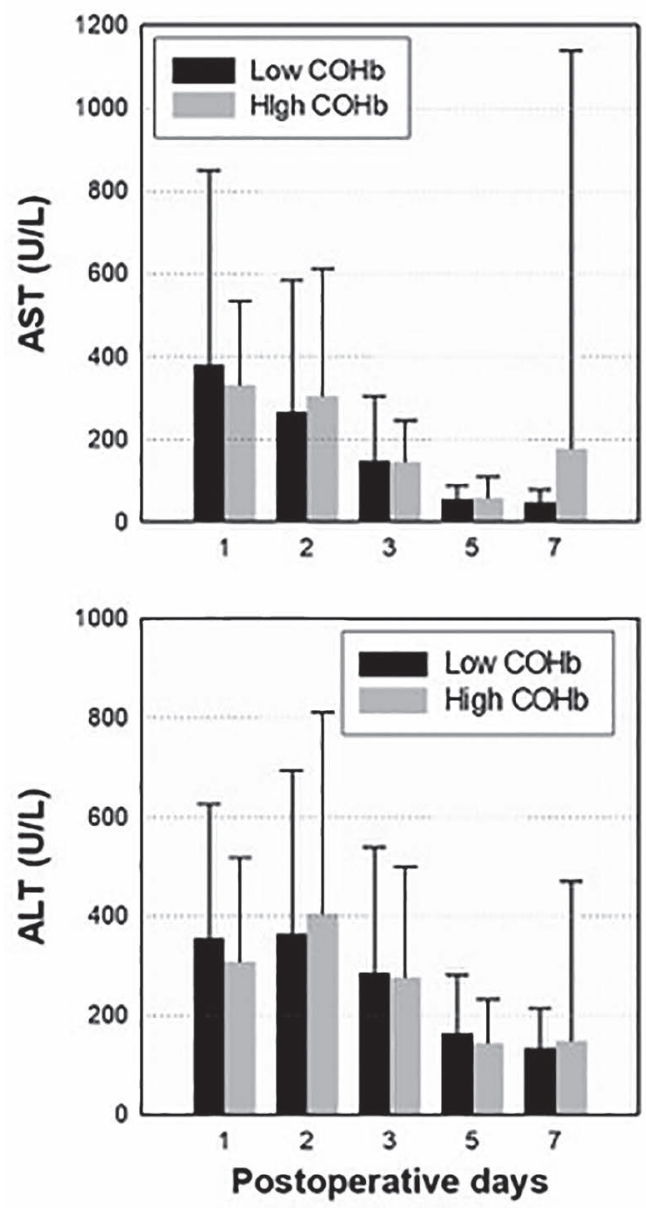

MetHb
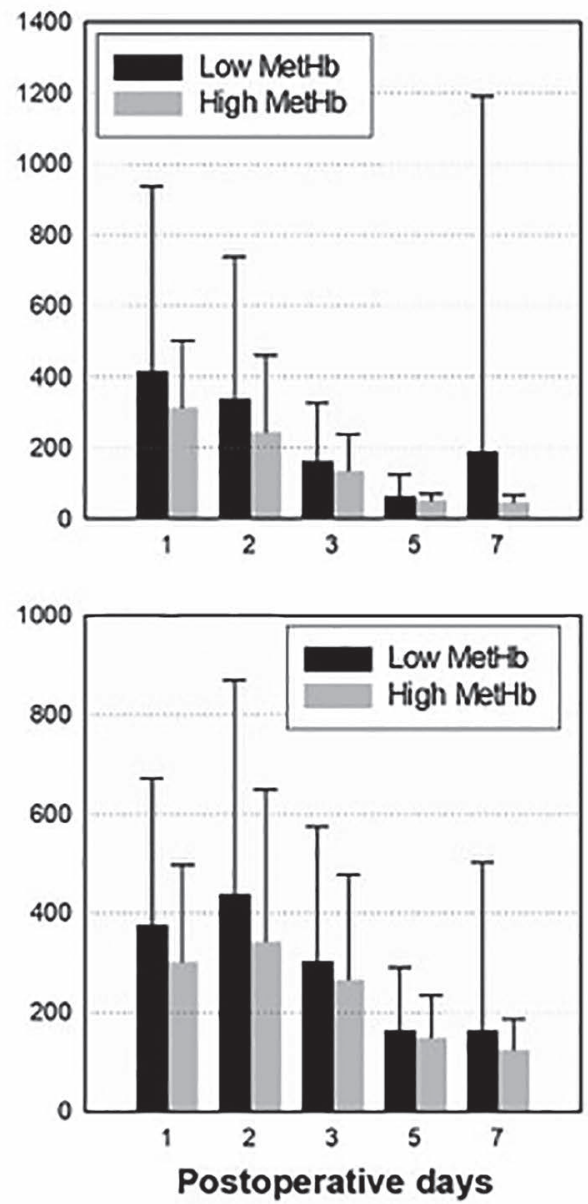

Fig. 3. Postoperative changes in aspartate aminotransferase (AST) and alanine aminotransferase (ALT) in each low and high group of $\mathrm{COHb}$ and $\mathrm{MetHb}$ after liver transplantation.

Data represent mean + SD by repeated measures ANOVA.

$\mathrm{COHb}$, carboxyhemoglobin; MetHb, methemoglobin.

Moreover, the ratio of smokers did not vary between the two groups, and there was no significant difference in $\mathrm{COHb}$ concentration after induction among non-smokers, ex-smokers, and current smokers.

The exact concentration of $\mathrm{COHb}$ in Cell Saver blood is difficult to determine. Slucky et al. (1996) argued that an increase in the concentration of $\mathrm{COHb}$ is due to transfusion of autologous blood collecting through the Cell Saver. In addition, $\mathrm{COHb}$ concentration changes in proportion to the degree of electric cauterization during spine surgery. However, $\mathrm{COHb}$ concentration 5 minutes after reperfusion is lower in recipients with Cell Saver blood transfusion than recipients without Cell Saver blood transfusion $(1.7 \pm 0.7 \%$ vs. $2.3 \pm 0.7 \%, p<0.001)$. Therefore, the use of Cell Saver did not affect the outcomes of the present study.

Pressors are inevitably used during liver transplantation for hemodynamic stability. CO produced by oxidative stress increases vasodilation and contributes to a higher demand for pressor. In fact, there were no significant differences in systemic vascular resistance 5 minutes and 1 hour after reperfusion in the two groups (Table 1). This indicates that the use of pressor corrects decreased systemic vascular resistance. The low $\mathrm{COHb}$ group has a lower MELD score, and the high $\mathrm{COHb}$ group has a higher MELD score. That is, the severity of liver disease is associated with increased $\mathrm{CO}$ production. Moreover, both $\mathrm{COHb}$ level at 5 minutes after reperfusion and MELD score had a weak correlation with the pressor dosage at 1 hour after reperfusion. Therefore, the concentration of $\mathrm{COHb}$ at 5 minutes after reperfusion and preoperative MELD score are weakly associated with hemodynamic instability during liver transplantation.

With oxidative stress such as operations and acute anemia, Hare et al. (2013) reported a small but consistent increase in MetHb levels. When oxidative stress increases, the enzyme system re-converting MetHb quickly reaches its limit and MetHb accumulates (Lee and Lee 2013). However, there has been little research on the time course of MetHb, such as affinity for hemoglobin and half-life. According to Hon et al. (2010), by 30 minutes after admin- 
istration of sodium nitrite, MetHb reached its maximum concentration. Thus, MetHb was used as an index of NO generation at 30 minutes after reperfusion. Table 4 shows no significant difference in the pressor dose used between low and high MetHb groups. Therefore, there is no relationship between hemodynamic instability after reperfusion and MetHb. Moreover, MetHb and MELD score had no relationship.

$\mathrm{CO}$ and $\mathrm{NO}$ differ in their effect on blood vessels and contributing to lower tension along with creation of cyclic guanosine monophosphate. According to Pannen and Bauer (1998), NO dilates the hepatic artery and does not affect the portal vein, whereas $\mathrm{CO}$ dilates the portal vein, but has little impact on the hepatic artery in the mouse liver. Suematsu et al. (1996) reported that NO dilates the hepatic artery more than the portal vein and $\mathrm{CO}$ dilates the portal vein more than the hepatic artery in human livers. According to our findings, $\mathrm{COHb}$ is more correlated with vasodilation during LDLT, compared with MetHb. Therefore, $\mathrm{CO}$ has a greater impact on hemodynamic instability by affecting the portal vein in LDLT than NO does by affecting the hepatic artery.

This study has several limitations. First, this report is a retrospective study at a single center. Therefore, bias due to unmeasured parameters is not ruled out. Another limitation is the time of MetHb division. Our reference is based on the MetHb concentration after administration of sodium nitrite, but this seems to be a different mechanism from the change in MetHb concentration due to hepatic ischemia/ reperfusion injury.

In conclusion, $\mathrm{CO}$ and preoperative MELD score are associated with hemodynamic instability during LDLT, while $\mathrm{NO}$ is not. Increased $\mathrm{COHb}$ after ischemia/reperfusion can predict hemodynamic instability. This is the first study about hemodynamic implications of $\mathrm{CO}$ and $\mathrm{NO}$ during LDLT. In the future, more research is needed to investigate the clinical significance of $\mathrm{CO}$ and $\mathrm{NO}$ during liver transplantation and postoperative management.

\section{Conflict of Interest}

The authors declare no conflict of interest.

\section{References}

Ali, Y., Negmi, H., Elmasry, N., Sadek, M., Riaz, A., Al Ouffi, H. \& Khalaf, H. (2007) Early graft function and carboxyhemoglobin level in liver transplanted patients. Middle East J. Anaesthesiol., 19, 513-525.

De Backer, D., Biston, P., Devriendt, J., Madl, C., Chochrad, D.,
Aldecoa, C., Brasseur, A., Defrance, P., Gottignies, P. \& Vincent, J.L. (2010) Comparison of dopamine and norepinephrine in the treatment of shock. N. Engl. J. Med., 362, 779-789.

De Las Heras, D., Fernandez, J., Gines, P., Cardenas, A., Ortega, R., Navasa, M., Barbera, J.A., Calahorra, B., Guevara, M., Bataller, R., Jimenez, W., Arroyo, V. \& Rodes, J. (2003) Increased carbon monoxide production in patients with cirrhosis with and without spontaneous bacterial peritonitis. Hepatology, 38, 452-459.

Gladwin, M.T., Crawford, J.H. \& Patel, R.P. (2004) The biochemistry of nitric oxide, nitrite, and hemoglobin: role in blood flow regulation. Free Radic. Biol. Med., 36, 707-717.

Hare, G.M., Tsui, A.K., Crawford, J.H. \& Patel, R.P. (2013) Is methemoglobin an inert bystander, biomarker or a mediator of oxidative stress. The example of anemia? Redox Biol., 1, 65-69.

Hayashi, M., Takahashi, T., Morimatsu, H., Fujii, H., Taga, N., Mizobuchi, S., Matsumi, M., Katayama, H., Yokoyama, M., Taniguchi, M. \& Morita, K. (2004) Increased carbon monoxide concentration in exhaled air after surgery and anesthesia. Anesth. Analg., 99, 444-448.

Hon, Y.Y., Sun, H., Dejam, A. \& Gladwin, M.T. (2010) Characterization of erythrocytic uptake and release and disposition pathways of nitrite, nitrate, methemoglobin, and iron-nitrosyl hemoglobin in the human circulation. Drug Metab. Dispos., 38, 1707-1713.

Lee, B., Baik, D., Yun, S., Shin, J., Kim, J., Yun, S., Kim, B., Kim, S., Shin, J. \& Song, I. (2007) Peripheral nitric oxide activity in patients with liver cirrhosis. Korean J. Med., 73, 251-251.

Lee, K. \& Lee, J. (2013) Antidote for acquired methemoglobinemia: methylene blue. J. Korean Med. Assoc., 56, 1084-1090.

Matsusaki, T., Morimatsu, H., Takahashi, T., Matsumi, M., Sato, K., Kaku, R., Sato, T., Yagi, T., Tanaka, N. \& Morita, K. (2008) Increased exhaled carbon monoxide concentration during living donor liver transplantation. Int. J. Mol. Med., 21, 75-81.

Pannen, B.H. \& Bauer, M. (1998) Differential regulation of hepatic arterial and portal venous vascular resistance by nitric oxide and carbon monoxide in rats. Life Sci., 62, 2025-2033.

Peterson, J.E. \& Stewart, R.D. (1970) Absorption and elimination of carbon monoxide by inactive young men. Arch. Environ. Health, 21, 165-171.

Slucky, A.V. \& Eismont, F.J. (1996) Carbon monoxide levels in cell saver salvaged blood exposed to electrocautery during lumbar spine surgery. J. Spinal Disord., 9, 404-408.

Suematsu, M., Wakabayashi, Y. \& Ishimura, Y. (1996) Gaseous monoxides: a new class of microvascular regulator in the liver. Cardiovasc. Res., 32, 679-686.

Takeda, R., Tanaka, A., Maeda, T., Yamaoka, Y., Nakamura, K., Sano, K., Kataoka, M., Nakamura, Y., Morimoto, T. \& Mukaihara, S. (2002) Perioperative changes in carbonylhemoglobin and methemoglobin during abdominal surgery: alteration in endogenous generation of carbon monoxide. $J$. Gastroenterol. Hepatol., 17, 535-541.

Tran, T.T., Martin, P., Ly, H., Balfe, D. \& Mosenifar, Z. (2007) Carboxyhemoglobin and its correlation to disease severity in cirrhotics. J. Clin. Gastroenterol., 41, 211-215. 